\title{
Self-Esteem Body Image And Self-Consciousness Among Women After Rejection Of Marriage Proposals
}

\author{
Humaira Iram \\ \& \\ Amina Muazzam \\ Department of Applied Psychology \\ Lahore College for Women University
}

\begin{abstract}
The purpose of this study is to identify the phenomena of marriage proposals rejection among working and non-working women. It is hypothesized that there is significant difference in self esteem, body image and self consciousness of working and nonworking women after rejection of marriage proposals. The sample was comprised of $(\mathrm{N}=170)$ women from which $(\mathrm{n}=79)$ was working women and $(\mathrm{n}=91)$ was nonworking women. Sample was recruited by using snowball sampling technique. Mix method research design was used in this study. The major tools of this study include Rosenberg Self-Esteem Scale (SES) by Rosenberg (1965), Body Image Scale (BIS) by Moeen, Muazzam \& Zubair (2013) Self-consciousness Scale revised (SCS-R) by Scheier \& Carver (1985). The findings showed that body image, proposals rejected by self, number of siblings, younger married sisters, low designation and old age are a predictor of proposals rejection faced by women. The other findings revealed that there is non-significant difference in self esteem, body image and self consciousness among working and non-working women after rejection of marriage proposals. It was also explored that there was non-significant relationship in self esteem, body image and self consciousness among women.
\end{abstract}

Keywords: Self-Esteem, Body Image, Self-Consciousness and Rejection of Proposals.

$$
\begin{aligned}
& \text { تلخيص }
\end{aligned}
$$

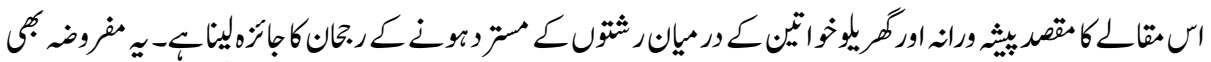

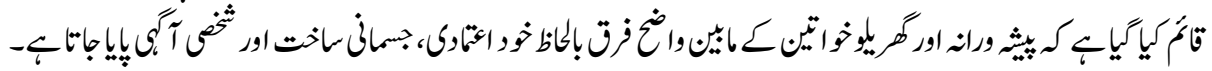

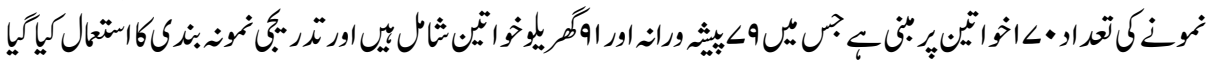

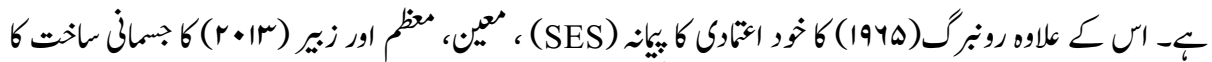

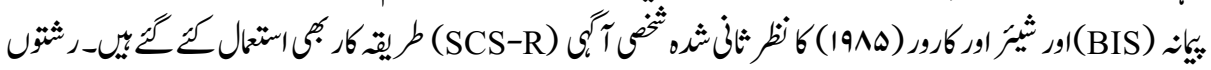

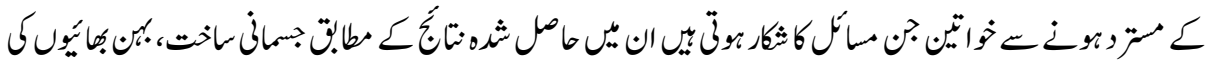

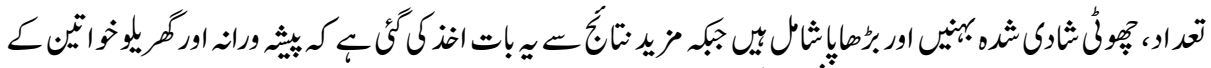

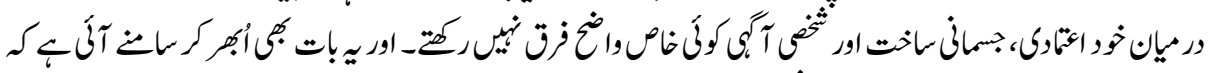

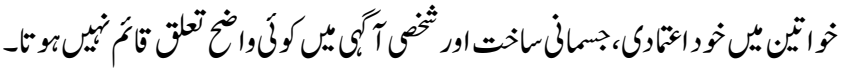

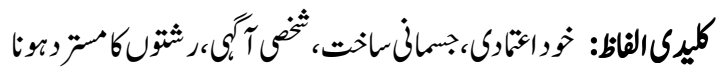


Proposal rejection has become a big problem for girls in Pakistani society. This is very sensitive phenomena since rejection directly affects self image and self-esteem of the girls. This study explores the phenomenon of rejection of proposals in the Pakistani context. Purpose of the study is to find out difference between groups i.e. working and non-working groups, in their self esteem, body image and self-consciousness. Relationship among self esteem, body image and self-consciousness is explored. Furthermore, this study explores the reasons of proposal rejection that help us to identify the root cause of psychological symptoms experienced by females when they face rejection (Rohner, 2004).

First of all, there is a dire need of understanding about the marriages insistence in Eastern and Western cultures. The processes of selecting a lifetime partner significantly differ between both cultures. In Western culture marriage is not the first step of beginning a relationship and their members of family are not concerned when an individual begins a relationship. Mates choose each other by the inter-personal attraction. On the other hand in Eastern cultures wedding are considered the pre-requisite for a relationship and it is typically organized by members of family. Arranged marriages are seen as an agreement between two families instead of two people, and are supported a contract wherever each side need to fulfill their obligations. Thus, arranged wedding isn't solely a bond of husband and wife but also a union of two families in Easterner cultures (Madathil, 1999).

Rejection refers to individuals' belief that their partner or parent does not really like, approve of, care about, or love them (Rohner, 2004). A research supported that people who reported relatively low investment in romantic relationships, anxious expectations of rejection predicted reduced involvement in close relationships with friends and romantic partners and in general, increased distress in and avoidance of social situations (Downey, Feldman \& Ayduk, 2000).

After facing rejection, people face many psychological symptoms e.g. hostility, aggression, passive aggression, or problems with the administration of hostility, dependence or defensive independence depending on the form, frequency, timing, and duration of rejection, impaired self-esteem, impaired self-adequacy, emotional unresponsiveness, emotional instability and negative worldview. Additionally postulates that the experience of interpersonal rejection is likely to be associated with anxiety, insecurity and cognitive distortions. Collectively these dispositions constitute one possible measure of overall psychological mal-adjustment. The experience of rejection can lead to a number of adverse psychological consequences such as loneliness, low selfesteem, aggression and depression. It can also lead to feelings of insecurity and a heightened sensitivity to future rejection (Rohner, 2004). 
People differ in the way they respond to rejection and common responses to perceived rejection include dejection, emotional withdrawal, hostility and jealousy. These negative behaviors associated with high rejection sensitivity adversely affect close inter-personal and romantic relationship. There are numerous harmful effects of rejection on cognitive performance, especially on tasks that require full control (Ayduk, et. al. 1999).

Jan \& Ashraf (2008) stated that Self-esteem has enormous influence on mental health of women. Self-esteem comprises of self-worth and self-image, which affects women's adjustment in various spheres of life. This paper presents relation of age, family income, and family type with self-esteem among women. In this context, 100 women were selected through multistage sampling method, administering questionnaire, and 'selfesteem scale for women' (SESW). The study reveals highly significant relation of family type with self-esteem in personal life of women. Significant differences are also found among women in joint, nuclear and extended families, concerning their self-esteem in family relations, career and overall self-esteem. Family income has also shown significant association with women's self-esteem in family relations.

Self-esteem is a positive or negative orientation toward oneself; an overall evaluation of one's worth or value. People are motivated to have high self-esteem, it indicates positive self-regard, not egotism. Self-esteem is only one component of self-concept, which Rosenberg defines as "totality of the individual's thoughts and feelings with reference to himself as an object." Besides self-esteem, self-efficacy or mastery, and self-identities are important parts of the self-concept (Rosenberg, 1965).

Self-esteem is generally considered the evaluative component of the self-concept, a broader representation of the self that includes cognitive and behavioural aspects as well as evaluative or affective ones. While the construct is most often used to refer to a global sense of self-worth, narrower concepts such as self-confidence or body esteem are used to imply a sense of self-esteem in more specific domains. It is also widely assumed that selfesteem functions as a trait, it is stable across time within individuals. Self-esteem is an extremely popular construct within psychology, and has been related to virtually every other psychological concept or domain, including personality (e.g., shyness), behavioural (e.g., task performance), cognitive (e.g., attributional bias), and clinical concepts (e.g., anxiety and depression). While some researchers have been particularly concerned with understanding the nuances of the self-esteem construct, others have focused on the adaptive and self-protective functions of self-esteem (Blascovich \& Tomaka, 1991).

Self esteem was the most important predictor of body dissatisfaction, with females with low self esteem experiencing more body dissatisfaction than those with high self-esteem. It is also noted that the impact of society, parents, girlfriends, and boyfriends, improved the prediction of body dissatisfaction, low self-esteem, and importance of appearance. 
Women have traditionally displayed a greater commitment to the pursuit of cultural standards of beauty compare to men. Women believe that having a slim body image is very important, and how they think that society portrays very slim women as beautiful and desirable and average women as overweight and obese. The research shows that the relationship between body image and self esteem is important for women. Body image is closely related to self esteem. There is very strong association between body image concerns and low self-esteem among adolescent girls, which has led to constructions of body image as an important aspect of female self-esteem (Huebscher, 2010).

A survey was conducted in (2013) by Saeed to determine the relationship between body image and self esteem. On the basis of total 52 samples from which two groups were made i.e. age group 1 (12 years -15years) and age group 2 (16 years- 19 years) the mean difference from the variables on concept of self esteem is 28.64 of age group 1 and 28.10 of age group 2. This shows that the result of the research is neutral, body image and self-esteem do not affect each other. From this study no relation was found between self-esteem and body image. It suggests that an adolescent's concept of his/her body image has little to affect his self-esteem.

Body image relates to how a person thinks and feels about his or her own body. Body image also refers to the way we see our body and the way we think that others see our body. Body Image is defined as a person's self feeling and perception about his/her own body that involves his/her physical look, facial appearance, maturity and other bodily features like height and weight (Moeen, Muazzam \& Zubair, 2013).

A research is conducted to find out the relationship between body image and self consciousness. Result highlighted that there is negative significant relationship between body image and self-consciousness. If the body image increases than the selfconsciousness decrease but Private and public self-consciousness correlated positively with each other (Theron, Nel \& Lubbe, 1991).

Self-consciousness is defined as the degree to which individuals habitually focus upon themselves (Fenigstein, Scheier, \& Buss, 1975). Self-consciousness is an ability that is unique to humans. Self-consciousness is the awareness of self, the self system, and the self as a social object. Except humans no other creature is considered to have power over the cognitive ability to be aware of the self in such a mode. In the personality literature, attention directed at the self has been conceptualized both as a state and a trait. Selfawareness is considered to be the state of self-directed attention. From an evolutionary viewpoint, self-consciousness is an ability that is unique to humans. Self-consciousness is the awareness of the self, the self-system, and the self as a social object. Except humans no other creature is considered to have power over the cognitive ability to be aware of the self in such a mode. Attention directed at the self has been conceptualized both as a state and a trait. Self-awareness is considered to be the state of self-directed attention (Fenigstein, et al., 1975). 
An investigation on relationship between public and private self-consciousness and social and personal aspects of identity was carried out by Cheek and Briggs (2009). Findings assume that public self-consciousness correlated significantly more strongly with social than with personal aspects of identity whereas private self-consciousness correlated significantly more strongly with personal than with social aspects of identity.

Rejecting the proposal is one of the biggest and social emerging problems in Pakistan. Although, there is not so much done on this area and in Pakistan this area of research is not encouraged. As research supported that rejection of proposal leads the females towards social anxiety and body dimorphic disorder Fang \& Hoffman (2006) and other psychological problems so, we can help females to boost up their self-esteem by ignoring all the societal stigmas. Rejection of a proposal not only impacts that woman but also her parents and even whole family. For women of a Pakistani society it's a very distressful experience and her whole functioning is disturbed so, this study will help them to overcome this stressful experience successfully.

\section{Significance of the Research}

The current study has significance with respect to global and Pakistani culture. Proposal rejection results in low self-esteem leading towards negative reactions in females it includes negative body image and a significant decrease in self-consciousness, These factors combined together create a lot of hurdles for females causing a decrease in their morale resulting in the emergence of negative thoughts which then have a considerable impact on their self-confidence shattering their personality and producing inferiority complex in females this limits them to act as a useful member of the family and as a drawback they lose their self-esteem and no longer consider themselves a worthy member of the society.

The objectives of the study are as follows:

1. To identify the causes of rejection of proposals among working and non-working women.

2. To find out the difference between self-esteem, body image and self-consciousness among working and non-working women after rejection of marriage proposal.

3. To find out the correlation between self-esteem body image and self-consciousness among working and non-working women after rejection of marriage proposals.

\section{Method}

Using the Mix method research design, during the first part of the study, focus group was conducted to identify the causes of rejection whereas, in second part of the study between group research designs was used to find out the difference in self esteem, body image and self-consciousness among women.

\section{Sample}

The sample was comprised of $(\mathrm{N}=170)$ women from which $(\mathrm{n}=79)$ was working women and $(n=91)$ was non-working women. The age range was 24 to 40 years. Sample was 
recruited by using snowball sampling technique. Only those participants were included who have experienced proposals rejection at least once. Non-working students and those who have completed their study and are still unmarried were taken as non-working sample.

\section{Variables and Measures Self-Esteem}

Self-esteem is a positive or negative orientation towards oneself; an overall evaluation of one's worth or value. People are motivated to have high self-esteem, and having it indicates positive self-regard (Rosenberg, 1989). The self Esteem was assessed by using Self Esteem Scale (SES) by Rosenberg (1965). The 10 items are answered on a four point scale ranging from strongly agree to strongly disagree.

\section{Body Image}

Body Image is defined as a person's self feeling and perception about his/her own body that involves his/her physical look, facial appearance, maturity and other bodily features like height and weight. The body image was assessed by using Body Image Scale (BIS) by Moeen, Muazzam \& Zubair (2013). The Body Image Scale (BIS) is a 35-item indigenous measure. The scale measures body image concerns among young adult females. There are three subscales of Body Image Scale i.e. bodily section: $\alpha=.909$, Emotional section: $\alpha=.909$, plan to sustain one's physical picture: $\alpha=.830$. The alpha coefficient of .951 was got for the BIS.

\section{Self-Consciousness}

Self-consciousness is defined as the degree to which individuals habitually focus upon themselves (Fenigstein, Scheier \& Buss, 1975). The Self-Consciousness was assessed by using Self consciousness Scale revised (SCS-R) by Scheier \& Carver (1985) is 22-item scales which evaluate a personal's personality-awareness in both social and personal conditions. The reliability of personal personality-awareness was 0.75 , social personalityawareness was .84 and public anxiety 0.84 .

\section{Procedure}

Permission was taken from the authors of all scales. Informed consent was taken from each of the individual participants. The researcher assured the participants confidentiality. This study consists of two parts. In first part we conduct Focus groups to find out the main causes of rejection and in second data was collected quantitatively. The participants were given Demographic Information Questionnaire (DIQ), Self-Esteem Scale (SES) Body Image Scale (BIS) and self-consciousness scale to find out the difference in self esteem, body image and self consciousness among working and non working women. Total time to fill the questionnaire was between 20-25 minutes. The participant was thanked for their cooperation. 


\section{Results}

Independent sample t-test was carried out to find out the difference in self esteem, body image and self consciousness among women after rejection of marriage proposals. Correlation was carried out to find the relationship between Self Esteem, Body Image and Self Consciousness among working Women after rejection of marriage proposals. Linear Regression was carried out to find out the predictor the causes of rejection.

Table: 1

Themes revealed during focus group data

\begin{tabular}{|c|c|c|}
\hline Working women & Non-working women & Working and non-working women \\
\hline High education & Health & Employed \\
\hline Dowry & Looks & Education \\
\hline Importance of boys & Dowry & Well groomed \\
\hline Society norms & Dark complexion & Job \\
\hline High status & Short heighted & High education \\
\hline Age factor & Glasses & Living standard \\
\hline High demands & Hearing add & Job \\
\hline \multicolumn{3}{|l|}{ Table 1 continued } \\
\hline Working women & Non-working women & Working and non-working women \\
\hline Short heighted & Proud & Caste system \\
\hline Media & Short heighted & Short heighted \\
\hline Caste system & Cast system & Dowry \\
\hline Beauty & Fashionable & Obesity \\
\hline Left handed & Job & Socioeconomic status \\
\hline Media & Liberal thinking & Average look \\
\hline High expectations & Obesity & Demands of society \\
\hline Job preference & Confused demands & Multiple demands of people \\
\hline Low self esteem & Inferiority complex & Irritation \\
\hline Frustration & Lack of abilities & Less belief in marriage \\
\hline Mental stress & Negative behaviors & Hopelessness \\
\hline \multirow[t]{4}{*}{ Jealousy } & Hopelessness & Depression \\
\hline & Depression & Anxiety \\
\hline & Less social & Refusal to marry \\
\hline & Low self esteem & Less social \\
\hline
\end{tabular}

\section{Demographic Information of Participants}

The mean age of the sample was 26 years approximately with SD of 3.22. Number of average siblings was approximately 4 . Number of average married sisters was 1 . Number of average married brother was also 1 approximately. Number of average unmarried sisters was approximately 2. Number of average unmarried brothers was 1 . Number of average younger married sister was 1 . The frequency and the percentage of working women were $43.9 \%$, and non-working women were $50.6 \%$. Joint family system was $27.2 \%$ and nuclear was $67.2 \%$. Unemployed was $50.6 \%$ and Govt. employ was $5.6 \%$ and private employ was $38.3 \%$. Single child was $15.0 \%$ and non-single child was $79.4 \%$. 
Table: 2

Mean differences between variables among women after rejection of marriage proposals $(\mathbf{N}=170)$

\begin{tabular}{|l|l|l|l|l|l|l|l|l|l|}
\hline & \multicolumn{2}{|c|}{$\begin{array}{c}\text { Working } \\
(\mathbf{n = 7 9 )}\end{array}$} & \multicolumn{2}{c|}{$\begin{array}{c}\text { Non-working } \\
(\mathbf{n = 9 1})\end{array}$} & & \multicolumn{2}{|c|}{$\mathbf{9 5 \%}$ CI } & \\
\hline Variable & $M$ & $S D$ & $M$ & $S D$ & $T$ & $p$ & $L L$ & $U L$ & $\begin{array}{c}\text { Cohen's } \\
d\end{array}$ \\
\hline SES & 22.77 & 4.40 & 22.74 & .50 & .06 & .95 & -1.10 & 1.17 & .009 \\
SCS-R & 46.51 & 8.71 & 46.41 & 7.60 & .07 & .93 & -2.39 & 2.59 & 0.01 \\
\hline BIS & 29.84 & 23.99 & 31.56 & 24.54 & -.45 & .67 & -9.07 & 5.65 & 0.07 \\
\hline CR & 8.96 & 5.57 & 11.83 & 4.82 & -3.51 & .00 & -4.45 & -1.28 & 0.55 \\
\hline Psy.Ch & 7.73 & 7.21 & 14.25 & 6.57 & -6.13 & .00 & -8.60 & -4.43 & 0.94 \\
\hline
\end{tabular}

$p<.05, p<.0$ 1Note. $\mathrm{M}=$ mean; $\mathrm{SD}=$ standard deviation; $\mathrm{t}=\mathrm{t}$ value $; \mathrm{P}=$ significance value; $\mathrm{CI}=$ confidence interval; $\mathrm{N}=$ Sample size; $\mathrm{n}=$ no of participants: Note. SES: Self Esteem Scale, SCS-R: Self Consciousness Scale- revised, BIS: Body Image Scale, CR: Causes of Rejection, Psy.Ch: Psychological Changes

The results suggest that there are non-significant differences in Self Esteem, Body Image and Self consciousness among working and non-working women after rejection of marriage proposals. Where as the result suggests that there is s significant difference in causes of rejection and psychological changes there is more psychological change among non-working women as compared to working women after rejection of marriage proposals.

Table: 3

Mean differences between self consciousness and its subscale among after rejection of marriage proposals $(\mathrm{N}=170)$

\begin{tabular}{|l|l|l|l|l|l|l|l|l|l|}
\hline & \multicolumn{2}{|c|}{$\begin{array}{c}\text { Working } \\
(\mathrm{n}=79)\end{array}$} & \multicolumn{2}{|c|}{$\begin{array}{c}\text { Non-working } \\
(\mathrm{n}=91)\end{array}$} & & & \multicolumn{2}{|c|}{$\underline{95 \% C I}$} & \\
\hline Variable & $M$ & $S D$ & $M$ & $S D$ & $T$ & $p$ & $L L$ & $U L$ & $\begin{array}{c}\text { Cohen's } \\
d\end{array}$ \\
\hline SCS-R & 46.51 & 8.71 & 46.41 & 7.60 & .07 & .93 & -2.39 & 2.59 & 0.01 \\
Pu.SCS & 16.92 & 3.57 & 16.85 & 3.58 & .12 & .88 & -1.00 & 1.16 & 0.01 \\
\hline Pr.SCS & 19.95 & 4.21 & 18.76 & 3.58 & .31 & .75 & -1.00 & 1.39 & 0.30 \\
\hline SA & 9.63 & 3.55 & 9.80 & 3.96 & -.29 & .77 & -1.30 & .97 & 0.04 \\
\hline
\end{tabular}

$p<.05, p<.0$ 1Note. $\mathrm{M}=$ mean; $\mathrm{SD}=$ standard deviation; $\mathrm{t}=\mathrm{t}$ value; $\mathrm{P}=$ significance value; $\mathrm{CI}=$ confidence interval; $\mathrm{N}=$ Sample size; $\mathrm{n}=$ no of participants: Note. SCSR:Self Consciousness Scale-revised, Pu.SCS: Public Self Consciousness Scale , Pr.SCS: Private Self Consciousness Scale, SA: Social Anxiety

Independent sample t-test was used to find out the mean difference in self consciousness and its sub-scale among working and non-working female after rejection of marriage proposals. The results suggest that there is non-significant difference in self 
consciousness, public self consciousness, private self consciousness and social anxiety among working and non-working female after rejection of marriage proposals.

Table: 4

Relationship between variables among women after rejection of marriage proposals $(\mathrm{N}=170)$

\begin{tabular}{|l|c|c|c|c|c|}
\hline Variables & $\mathbf{1}$ & $\mathbf{2}$ & $\mathbf{3}$ & $\mathbf{4}$ & $\mathbf{5}$ \\
\hline SES & - & -.08 & -.09 & -.14 & -0.16 \\
\hline SCS-R & - & - & .05 & $.17 *$ & .17 \\
\hline BIS & - & - & - & .05 & -.02 \\
\hline CR & - & - & - & - & $.33^{*} *$ \\
\hline Psy.Cha & - & - & - & - & - \\
\hline
\end{tabular}

$* p<.05, * * p<.01$ Note. SES: Self Esteem Scale , SCS-R:Self Consciousness Scalerevised, BIS: Body Image Scale, CR: Causes of Rejection, Psy.Ch: Psychological Changes

Pearson product moment correlation was used to find out the relationship between self esteem, body image, self consciousness, causes of rejection and psychological change among working and non-working women after rejection of marriage proposals. The results suggest that there is a significant negative relationship between self esteem and psychological change among women after rejection of marriage proposals. When selfesteem is high then psychological changes are low among women. There is also a significant positive relationship in self consciousness, causes of rejection and psychological changes among women after rejection of marriage proposals. When selfconsciousness is high then psychological changes and causes of rejection are also high. There is non-significant relationship in body image, self-consciousness, self-esteem and psychological change among women after rejection of marriage proposals. Similarly the relationship between self esteem and causes of rejection is insignificant as well.

Table: 5

Relationship between Self consciousness and its subscale among women after rejection of marriage proposals $(\mathrm{N}=170)$

\begin{tabular}{|l|c|c|c|c|}
\hline Variables & $\mathbf{1}$ & $\mathbf{2}$ & $\mathbf{3}$ & $\mathbf{4}$ \\
\hline SCS-R & - & $.79^{* *}$ & $.78^{* *}$ & $.59^{* *}$ \\
\hline Pu.SCS & - & - & $.57^{* *}$ & $.17^{*}$ \\
\hline Pri.SCS & - & - & - & .10 \\
\hline SA & - & - & - & - \\
\hline \multirow{2}{*}{$p<.05, * * p<.01$} & Note SCS-R: Self Consciousness Scale- revised, Pu.SCS: Public Self
\end{tabular}
Consciousness Scale, Pr.SCS: Private Self Consciousness Scale, SA: Social Anxiety

Pearson product moment correlation was used to find out the relationship between selfconsciousnesses, public self-consciousness, private self-consciousness and social anxiety among women after rejection of marriage proposals. The results suggest that there is significant positive relationship in self-consciousness, public self-consciousness, private selfconsciousness and social anxiety among women after rejection of marriage proposals. When self-consciousness is high then public self-consciousness and private self-consciousness is 
also high and social anxiety as well. There is non-significant relationship in private selfconsciousness and social anxiety among women after rejection of marriage proposals.

Table: 6

Table showing multiple Regression Body Image Scale, Proposals Rejection faced, designation, no. of siblings, younger Married sisters, Age

\begin{tabular}{|l|c|c|c|c|}
\hline Predictors & Dependent & Variable & PRF & Beta \\
\hline BIS & $B$ & $S E$ & $.16^{*}$ & 2.23 \\
\hline PRBS & .02 & 2.88 & $.16^{*}$ & 4.02 \\
\hline NOS & .16 & 2.93 & $.15^{*}$ & 4.26 \\
\hline YMS & .18 & 2.93 & $3.91^{*}$ & 30.34 \\
\hline Designation & 1.96 & 2.73 & $-.16^{*}$ & 4.85 \\
\hline Age & -.99 & 2.92 & $.23^{*}$ & 9.40 \\
\hline T & .21 & 2.88 & & \\
\hline P & 2.41 & & & \\
\hline R Square & .00 & & & \\
\hline R & .23 & & & \\
\hline
\end{tabular}

Note: * P<0.05 Note, CPR: Causes of proposals rejection, BIS: Body Image Scale, PFR:

Proposals Rejection faced, NOS: no. of siblings, YMS: younger Married sister, PRBS: proposals rejected by self.

Multiple Regressions was carried out to find the predictors of proposals rejection faced by women, Body Image disturbance, proposals rejected by self, more number of siblings, more younger married sisters low designation and being overage are significant predictors of proposals rejection.

\section{Discussion}

The present research was conducted to find out the difference in self-esteem, body image and self-consciousness among working and non-working women after rejection of marriage proposals. Various studies propose that male and female separate in their essential wellspring of self-regard, with female being more affected by connections and male being more impacted by target achievement. As far as another remarkable gender difference in emotions about the self over the lifespan, female have a tendency to have lower self-perception fulfilment than male. Female are more probable than male to assess particular body includes contrarily, to endeavour weight reduction, to report tension about the assessment of their physical appearance, and to have cosmetic surgery (Heatherton, 2001).

To find out the causes of rejection three focus group were conducted. The first focus group was carried out with working women, second focus group was conducted with 
non-working women and the third focus group was conducted with both working and non-working women to find out the causes of rejection. And the responses of the participants were almost the similar there was a slight difference in the responses of the participants. And the causes of rejection are Socio-economic status, poverty, Obesity, average look, Job, attitude, high education, not well groomed, high status, working women, average education. The psychological changes after rejection were also find out. Psychological changes after rejection are Inferiority complex, anger, lack of abilities, irritation, less belief in marriage hopelessness, depression, anxiety, irritation, refusal to marry and less social interaction are the main psychological changes. Richman and Leary (2009) carried a survey on responses to prejudices, stigma, and other forms of interpersonal refusal. Furthermore, the outcomes demonstrate that individuals' responses to dangers to social acknowledgment and having a place as they happen in the connection of assorted phenomena, for example, rejection, separation, segregation, disloyalty, and belittling. Individuals' prompt responses are very comparative crosswise over diverse types of rejection as far as negative influence and brought down self-regard. Then again, taking after these quick reactions, individuals' responses are affected by understandings of the rejection experience that foresee three unmistakable thought processes in prosocial, harmful, and socially ignore behavioural reactions.

Galen and Underwood (1997) stated that communal violent behaviour is directed in the direction of harming another's self-worth, socio-economic status, through structures such the same as vocal refusal, pessimistic facial look or physical appearances, additional nondirect structures insulting words and social withdrawal. All actions have a general objective of damaging, which comes out to be the center of knowing women violent behaviours.

It was hypothesized that there is significant difference in self esteem of working and nonworking women after rejection of marriage proposals. And the current finding shows that there is non-significant difference in self esteem of working and non-working women. Previous researches also support our findings. Dongen (1996) conducted a research on Quality of life and self-esteem in working and nonworking persons with mental illness. And the result shows that significant difference in overall quality of life was not found, but workers scored higher on all but one quality of life sub-scale. There were no significant differences in self-esteem quality of life or valuing of work based on demographic factors. No significant differences in drug attitudes were found based on work status.

And there is significant difference in family type (joint and nuclear) among women after rejection of marriage proposals. And our findings similar to the previous research. Jan and Ashraf (2008) stated that noteworthy relationship type of the family by means of selfworth in private life of female. Noteworthy dissimilarity also exists with female in combined, non-combined and extended relatives, regarding their sense of worth in relations, professional living and in general self-worth. Income of the family has also revealed note-worthy relationship with female's self-worth in relations of the family. 
It was hypothesized that there is significant difference in body image on working and non-working women after rejection of marriage proposals. The current result shows that there is non-significant difference in body image of working and non-working women. Previous research is not supporting our finding. Jalees and Run (2014) explores how television publicity, self-worth and religiosity manipulate self-perception of Pakistani customers. A positive association among contact to television and self-perception was found whereas negative manipulate was established among self-worth and self-perception. No association was established among religiosity and self-perception. The finding revealed combined outcomes than the previous literature.

The findings of this research contradict with previous research because the participant of the research was not dissatisfied with their body image both working and non-working. They were already slim and smart and have a positive attitude towards their body image. Therefore, research findings do not match to the previous researches. Black female are fewer possible to believe themselves overweight and are much pleased by their body mass as compared to white female in spite of the reality that black female are two time as possible to be overweighed. These female also label huge black physical look more definitely as compared to white female labelling huge white physical appearance (Hebl \& Heatherton, 1998).

It was hypothesized that there is significant relationship in self-consciousness, public selfconscious, private self-consciousness and social anxiety of working and non-working women. The current findings revealed that significant positive relationship in self-consciousness, public self-consciousness, private self-consciousness and social anxiety among working and non-working women after rejection of marriage proposals. Previous researches also support our findings. Kwon (1992) accounted on young living up and academy learners. Findings showed that physical awareness is directly linked to community personality awareness and social nervousness but not to public personality awareness.

A different survey accounted that community self-awareness connected considerably more powerfully with societal as compared to individual features of uniqueness while personal self-awareness connected notably much powerfully with private as compared to public features of uniqueness (Cheek \& Briggs, 2009).

One more study reveals that individual high in personality awareness, being much conscious of how they look by features, would be more responsive and respond more adversely to the rejection than people low in reluctance. In addition, it was found that mindfulness expands the negative reaction to the negative assessment and had a tendency to build the energy of the positive assessment (Fenigstein, 1979).

It was hypothesized that there is significant relationship in self-esteem and body image among women. And the finding showed that there is non-significant relationship in self- 
esteem and body image among women. Previous literature also supports our findings as well. A survey was conducted in (2013) by Saeed to focus the relationship between selfperception and self regard. This demonstrates that the consequence of the exploration is unbiased, self-perception and self regard don't influence one another. From this study no connection is found between self-regard and self-perception. It recommends that a preadult's idea of their self-perception has practically no impact on their self regard.

It was hypothesized that there is significant relationship in body image and self consciousness among women. And current finding showed that there is non-significant negative relationship in self esteem and self consciousness among women. Previous research supports the direction of the relationship of our research finding. Theron, Nel \& Lubbe (1991) directed an exploration to figure out the connection between selfperception and reluctance and results uncovered that there is huge negative relationship between self-perception and hesitance furthermore between self-perception and social uneasiness. Open and personal hesitance absolutely corresponded with one another and social tension also. Both males and females essentially differ just on social tension.

It was hypothesized that there is significant relationship in self-esteem and selfconsciousness among women. And current finding revealed that there is non-significant relationship in self-esteem and self-consciousness among women. Previous research not supported our finding. A survey on self-regard was directed to look at the connection between self-regard and the Big Five identity measurements. It was observed that high self-regard people were psychologically steady, outgoing people, and reliable and were to some degree pleasing and open to practice. Regardless of a wide look for potential middle people and arbitrators of this regular example, the relations between self-regard and the Big Five to a great extent split age, gender, socioeconomic status, civilization and ethnic group. High self-regard people had a tendency to characteristic of socially attractive to them, and this penchant to some degree interceded relations between the Big Five and self-regard (Robins, Tracy, Trzesniewski, Potter \& Gosling, 2001)

\section{Conclusions}

In this study we find that there is non-noteworthy difference in self-regard, selfperception and self-awareness among working and non-working women after rejection of marriage proposals. It implies that both working and non-working women are satisfied by their self-perception. What's more, they have a same level of self regard and selfconsciousness. What's more, there is additionally non-noteworthy relationship in selfregard, self-perception and self-awareness among working and non-working women after rejection of marriage proposals. It demonstrates that self-regard has no impact the selfperception and self-awareness of female. They are not connected with one another. Furthermore, the reasons for rejection are various. Some fundamental reasons are SES, neediness, heaviness, normal look, job, high instruction, not all around prepped, rich individuals, education and designation. Furthermore, the mental changes after rejection 
were discovered additionally. Mental changes after rejection are Inferiority complex, outrage, absence of capacities, disturbance, less confidence in marriage misery, depression, tension, bothering, refusal to wed; less social are the basic mental changes.

\section{Limitations and Recommendations}

The present research has few limitations and recommendations. First of all, the sample size was not large enough to generalize on whole population. So many difficulties faced in order to find out the females according to inclusion and exclusion criteria. The participants were drawn from one city of Pakistan i.e. only from Lahore. The duration of the study was small. It was also observed that females were hesitant to answer the question whether they face rejection or not. They were not agreed to respond about personal questions. Demographic information contain questions about reason for refusal of the proposal, due to which they feel hesitant. In fact, many of the females did not respond to this question. Response rate was below average that's why it took too much time to gather data.

Recommendations in the light of these limitations are given for future researches regarding betterment of the research work. These variables should be investigated on a large sample to make reliable generalization. More time should be given for research work. Data should be collected from the large area of Pakistan. Experienced with the concerned field will improve the understanding. Demographic information should not contain extra personal information. There must be some qualitative exploration of this phenomenon for the better understanding of this phenomenon.

\section{Implications of the study}

Some implementations for practice and future research are to use a larger sample base and to take male/female issues into account. Findings of this research study will prove beneficial for health psychologist as well as for counselors for providing better knowledge about this vital component of rejection and its important predictors. An understanding of all these aspects will provide a better insight into the self image and self-consciousness problems of rejected women.

\section{References}

Ayduk, D., Downey, G., Testa, A., Yen, Y. \& Shoda Y. (1999). Does Rejection Elicit Hostility in High Rejection Sensitive Women, Social Cognition, vol.17, pp.245-271.

Blascovich, J. \& Tomaka, J. (1991). Measures of Self-Esteem. Measures of Personality and Social Psychological Attitudes, Academic Press, http://www.macses.ucsf.edu/ research/psychosocial/selfesteem.php.

Cash,T.F., Morrow, J.A. \& Hrabosky, J.I. (2004). How Has Body Image Changed? A Cross- Sectional Investigation of College Women and Men from 1983 to 2001, Journal of Consulting and Clinical Psychology, vol.6, pp.1081-1089. 
Cheeks. M.J. \& Briggs. R.S. (2009). Self-Consciousness and Aspects of Identity, Journal of Research in Personality, vol.16:4, pp.401-408.

Doherty, G. \& Schlenker, B. R. (1991). Self-Consciousness and Strategic SelfPresentation, Journal of Personality, vol.59, pp.1-18.

Dongen, V. (1996). Quality of Life and Self-Esteem in Working and Non-Working Persons with Mental Illness, Community Mental Health, vol.32:6, pp.535-548.

Downey, G. Feldman, S. \& Ayduk, O. (2000). Rejection Sensitivity and Male Violence in Romantic Relationships, Personal Relationships, vol.7, pp.45-61.

Fang. A. \& Hofmann, S. G. (2006). Relationship between Social Anxiety Disorder and Body Dysmorphic Disorder, Clinical Psychology, vol.30, pp.1040-1048.

Fenigstein, A., Scheier, M. F. \& Buss, A. H. (1975). Public and Private SelfConsciousness: Assessment and the Theory. Journal of Consulting and Clinical Psychology, vol.36, pp.1241-1250.

Galen, L. \& Underwood, J.C. (1997). The Relationship between Self-Esteem and Indirect Aggression in the Work Place, Journal of Humanities and Social Sciences, vol.1:1, pp.126-136.

Heatherton, T. F. (2001). Body Image and Gender, International Encyclopaedia of the Social and Behavioural Sciences, Oxford, UK: Elsevier, vol.2, pp.1282-1285.

Hebl, M. \& Heatherton, T. F. (1998). The Stigma of Obesity in Women: The Difference is Black and White. Personality \& Social Psychology Bulletin, vol.24, pp.417-426.

Huebscher, B. (2010). Relationship between Body Image and Self-Esteem Among Adolescent Girls. A Research Paper Submitted in Partial Fulfilment of the Requirements for the Master of Science Degree In School Counselling, University of Wisconsin Stout Menomonie, WI.

Jalees, T. \& Run, E.C.D. (2014). Body Image of Pakistani Consumers, Journal of Management Sciences, vol.1:1, pp.16-34.

Jan, M. \& Ashraf, A. (2008). An Assessment of Self-Esteem among Women, Extension and Communication, Institute of Home Science, University of Kashmir, India, vol.2:2, pp.133-139

Kwon. Y. (1992). Body Consciousness, Self-Consciousness, and Women's Attitudes toward Clothing Practices. Journal of Social Behaviour and Personality, vol.20, pp.192-206. 
Madathil, J. (1999). Importance of Marital Characteristics and Marital Satisfaction: A Comparison of Asian Indians in Arranged Marriages and Americans in Marriages of Choice. Family Journal, New York: Academic Press, vol.16, pp. 222-230.

Moeen, T., Muazzam, A. \& Zubair, B. (2013). Development and Validation of Body Image Scale (BIS) For Young Adult Females, Pakistan Journal of Social and Clinical Psychology, vol.1, pp.52-58.

Richman, S.L. and Leary, M.R. (2009). Reactions to Discrimination, Stigmatization, Ostracism and Other Forms of Interpersonal Rejection. A Multi Motive Model. Psychol Rev, vol.116:2, pp.365-383.

Robins, R. W., Tracy, J. L., Trzesniewski, K. H., Potter, J. \& Gosling, S. D. (2001). Personality Correlates of Self-Esteem, Journal of Research in Personality, vol.35, pp.463-482.

Rohner, R. P. (2004). The Parental Acceptance-Rejection Syndrome: Universal Correlates of Perceived Rejection. American Psychologist, vol.59, pp.827-840.

Rosenberg, F. (1965). The Rosenberg Self-Esteem Scale. Department of Sociology, http://www.socy.umd.edu/quick-links/rosenberg-self-esteem-scale

Saeed, T. (2013). Relationship between Body Image and Self Esteem. College of Home Economics and Management, Quaid-i-Azam University, Islamabad, Pakistan, vol.6:1, pp.1-36.

Theron, W. H., Nel, E.M. \& Lubbe, A. J. (1991). Relationship between Body Image and Self-Consciousness. Perceptual and Motor Skills, vol.73:3, pp.979-83.

Humaira Iram is Student in the Department of Applied Psychology Lahore College for Women University, Lahore.

Dr. Amina Muazzam is an Assistant Professor in the Department of Applied Psychology Lahore College for Women University, Lahore. 